\title{
EL SECTOR FORESTAL CHILENO: \\ POLITICAS, DESARROLLO DEL RECURSO Y \\ EXPORTACIONES
}

Daniel Wisecarver (*)

Sergio Tardones M. $(* *)$

\section{RESUMEN}

El siguiente artículo analiza el rol que ha tenido la política económica en el surgimiento del sector forestal chileno como una de las fuentes líderes del crecimiento económico. Se consideran en forma separada las políticas específicas del sector y las políticas económicas generales. Las primeras, diseñadas para promover la creación del recurso forestal a través de estímulos fiscales para la plantación y manejo del mismo, han demostrado ser efectivas y muy superiores a las existentes con anterioridad.

Sin embargo, la producción y exportación de productos forestales en niveles significativos no está garantizada por la sola presencia del recurso forestal. La gran expansión en la produc. ción y exportación de estos productos, desde 1974 al presente, es atribuible al conjunto de políticas económicas generales, en especial la apertura de la economía chilena al comercio internacional.

Se concluye que la mantención de estos elementos de política económica es indispensable para la continuación del crecimiento del sector forestal chileno.

\begin{abstract}
This paper analyzes the role that economic policy has played in the emergence of Chile's forestry sector as a leading source of economic growth. Two separate sets of policy measures are considered. First are sector-specific policies designed to promote the creation of the forest resource itself through fiscal stimuli for plantation and forestry management. The evidence is overwhelming that the incentives provided to the private sector by $D . L$. 701 , have been far more effective in generating forestry plantations than the tax benefits granted under previous legislation.

However, the mere presence of forest resources is not by itself sufficient to guarantee significant levels of production and exportation of forestry products. Rather, the tremendous expansion in production and exports of these products from 1974 to present is attributable to the second set of general economic policy measures, particularly the opening of the Chilean economy to international commerce.

It is concluded that the maintenance of these general elements of economic policy is indispensable for the continued future growth of Chile's forest and forest-products industries.
\end{abstract}

(*) Profesor Instituto de Economía, Pontificia Universidad Católica de Chile.

(**) Ingeniero Civil. División Estudios Económicos. Instituto Forestal. Huérfanos 554. Santiago. Chile. 


\section{INTRODUCCION}

Desde hace ya más de cincuenta años, el bosque chileno ha despertado fuerte interés y grandes esperanzas como una fuente potencial de riqueza para el pais. De hecho, las proyecciones más optimistas afirman que en el futuro el recurso forestal reemplazaria al cobre como el principal producto de exportación de Chile. Por eso, varios gobiernos sucesivos han promulgado y mantenido políticas de fomento de la actividad forestal, y tanto el sector público como el privado han desarrollado una compleja y extensa infraestructura industrial, caminera y portuaria para poder aprovechar dicho recurso.

A lo largo de los últimos diez a doce años, las expectativas respecto al potencial del sector parecen haber comenzado a realizarse, tal como se puede apreciar con referencia a una serie de hechos que vienen apareciendo uno tras otro. Primero, de acuerdo con un informe del Banco Mundial (Banco Mundial, 1986). Chile posee una de las plantaciones forestales más grandes del mundo, y en respuesta a las políticas de fomento forestal, su bosque de Pino Radiata, que consiste en aproximadamente 1,2 millones de hectáreas al final de 1987, es el más grande del mundo, habiendo sobrepasado en $20 \%$ y $88 \%$, respectivamente, las plantaciones de Nueva Zelandia y Australia ya en 1985 .

Segundo, en los últimos meses varias inversiones importantes y cuantiosas en el sector forestal han sido emprendidas no sólo por las empresas chilenas ya establecidas sino también por otras que han decidido incursionar en el sector y, aún más notoriamente, por empresas y otros inversionistas extranjeros, en especial neozelandeses y japoneses. Los proyectos anunciados, muchos ya en marcha, incluyen la construcción de nuevas plantas de celulosa, junto con la expansión y modernización de las antiguas, la adquisición de plantaciones de Pino Radiata y de tierras aptas para la forestación, y la construcción de instalaciones portuarias para el embarque de astillas.

Tercero, y cruzando ya la linea entre proyecciones y realizaciones, las exportaciones de productos forestales han experimentado un auge notable (INFOR-CORFO, Junio 1987) en los últimos años.

Entre 1983 y 1987 estas exportaciones crecieron al ritmo anual del 15,2\% y durante 1988 totalizaron un valor de US\$ 730 millones, sobrepasando en un $26,5 \%$ a las de 1987 . Hoy en día, todos los puertos de la VIII Región están físicamente llenos de productos que esperan ser embarcados: trozos de madera aserrable, madera aserrada y dimensionada, madera pulpable (metro ruma) y verdaderas montañas de astillas. De hecho, existe preocupación en cuanto a que pronto la capacidad de los puertos comience a constituir el único cuello de botella significativo que restrinja el volumen de las exportaciones forestales.

Dado que el sector forestal aparentemente representa un ejemplo en el cual las mejores esperanzas se están haciendo realidad, el propósito del presente trabajo es resumir la evolución del sector, documentar las causas del éxito que el país está empezando a gozar e indicar proyecciones mínimas del potencial exportador que el recurso forestal significa para Chile. En la siguiente sección, se presenta una breve historia de la evolución del sector hasta 1974. Después, se analizan las medidas de política introducidas por el gobierno actual que más han incidido en el desarrollo del sector forestal.

Es importante enfatizar, antes de comenzar, que tanto bajo los gobiernos anteriores como bajo el actual, las políticas que han influido en la evolución del sector deberían separarse, por lo menos para propósitos analíticos, en dos grandes subconjuntos. Primero, durante más de medio siglo todos los gobiernos chilenos han instituido y mantenido politicas de fomento del recurso físico del bosque; en este sentido, los cambios introducidos en 1974 fueron más bien de forma (y de efectividad ex post) y no tanto de fondo. Segundo, las medidas generales de po- 
lítica económica, así como su filosofía subyacente, han sido factores determinantes en la manera (y la intensidad) en que el recurso forestal ha sido aprovechado. A este respecto, la conducción económica del gobierno actual ha significado un cambio drástico y de fondo, frente a las políticas anteriores. Como se verá en la sección III, el sector forestal ha sido uno de los grandes beneficiarios de este cambio.

Finalmente, cabe señalar que el análisis del presente artículo se centra en el Pino Radiata, que es lejos la especie forestal económicamente más importante del país. Sin embargo, debe tenerse presente que casi todas las políticas referidas en la discusión que sigue también se aplican a las otras especies y, para citar sólo un ejemplo de creciente interés, hay informes (pero todavía no cifras) de que las plantaciones de Eucalipto habrían aumentado notablemente durante los meses recién pasados. Este desarrollo, junto con el bosque de Eucalipto ya existente, de casi 60.000 hectáreas (a Diciembre de 1986) (INFOR-CORFO, Junio 1987), tendrá implicancias significativas para el sector forestal chileno del futuro.

\section{EVOLUCION HISTORICA DEL SECTOR FORESTAL EN CHILE}

Debido a su geografía, clima y dotación de bosques nativos, Chile tiene una larga historia como país productor y exportador de madera y otros derivados del recurso forestal. Aún después de décadas de explotación, en 1985 se estima el área del bosque nativo en más de $20 \mathrm{mi}$ llones de hectáreas, 13 millones en parques nacionales y reservas forestales y 7,6 millones de hectáreas de bosques comerciales (Banco Mundial 1986, pág. 68). Más aún, aunque las cifras históricas respecto a la explotación de este recurso son escasas, en 1930 el país produjo 111.400 $\mathrm{m}^{3}$ de madera aserrada (el $99,5 \%$ proveniente de bosques nativos) y exportó $28.800 \mathrm{~m}^{3}$.

Sin embargo, las perspectivas económicas del sector forestal en Chile se basan en la explotación del bosque comercial proveniente de las plantaciones de diversas especies, predominantemente el Pino Radiata. Originario de la península de Monterrey, México, el Pino Radiata fue introducido hace unos 100 años en Chile, donde, debido a las condiciones climáticas y de suelos, especialmente en las Regiones VII a IX, goza de un crecimiento notablemente más rápido que en su tierra nativa y en otras partes del mundo. Como consecuencia de eso, en Chile el período de corta, o rotación, sería para la madera aserrada de 22 a 25 años y para la madera pulpable de 18 a 20 años, mientras en países forestales como Estados Unidos, Suecia y Canadá los mismos volúmenes comerciables requieren hasta 100 años (Aninat, Claro y Méndez, 1982, pág. 38). Esta rotación constituye la base de las ventajas comparativas que Chile tiene frente a los otros productores competitivos.

Frente a tal ventaja natural, y quizás como parte de la estrategia general de activismo estatal que comenzó en la época, en Julio de 1931 el gobierno chileno promulgó el D.L. 4.363, la llamada "Ley de Bosques", con el objeto, por un lado, de fomentar la forestación, a través de exenciones tributarias y la participación activa y directa del estado y, por otro lado, de lograr una protección adecuada del medio ambiente relacionado con el sector.

La exención tributaria fue simple, directa y generosa: para plantaciones en terrenos clasificados como "forestales", se estableció la exención total, por el plazo de 30 años desde la plantación, de los impuestos territorial, de primera categoría, global complementario, tasa adicional y aquellos sobre herencias, donaciones, etc. Con este incentivo y la participación estatal,

(1) Banco Mundial, Op. cit. Inventario de las Plantaciones Forestales de la Zona Centro Sur de Chile. Instituto Forestal. Informe Técnico $\mathrm{N}^{\circ}$ 24, Santiago, Mayo de 1966. Estad ísticas Forestales 1980, INFOR, Santiago, Agosto 1980. Gana, J. Análisis y Perspectivas del Sector Forestal. Tesis Ing. Ind. Universidad de Chile. Facultad de Ciencias Físicas y Matemáticas Santiago, 1982. Subcomisión de Inversiones Forestales. Disponibilidad de Madera de Pino Radiata en Chile. 1986-2015, INFOR-CORFO, Santiago, Mayo 1987. Estad ísticas Forestales 1986. INFOR, Santiago, Junio 1987. 
entre 1931 y 1974 se logró un ritmo significativo y creciente de plantaciones de bosques̀ artificiales, de acuerdo con cifras aproximadas que aparecen en el Cuadro 1. Es necesario enfatizar que estas cifras, especialmente hasta 1975, sólo pueden entenderse como aproximaciones, debido a la falta de mediciones sistemáticas antes de esa fecha. Existen varios estudios respecto a las tasas de plantaciones y la superficie total del bosque chileno de Pino Radiata (1), pero desafortunadamente no son consecuentes entre sí.

Para reflejar la trayectoria del flujo de plantaciones entre 1931 y 1955 , se ha recurrido a información publicada por INFOR en 1966, respecto a la distribución por edades de las plantaciones de Pino Radiata que habrian existido en el período 1963-1965 (ver Cuadro 5). Estas cifras permitirian inferir valores mínimos de plantaciones por quinquenio entre 1931 y 1954, tal como se indica en el Cuadro 1.

Después, para las plantaciones anuales entre 1955 y 1964, el Cuadro 1 presenta las cifras del Banco Mundial, ya que ellas son razonablemente consecuentes con las estimaciones de INFOR utilizadas para los quinquenios anteriores. Finalmente, para los años 1965 hasta 1985, se confía en los cálculos efectuados por la Subcomisión de Inversiones Forestales, ya que reflejan la información más actualizada y más ampliamente citada por los sectores públicos y privado. Aceptando esta serie, confeccionada de la manera descrita y sin una evaluación crítica más detallada, se puede concluir entonces que entre 1940 y 1974, se habria plantado un promedio anual de 11.373 hectáreas, con un fuerte aumento registrado a partir de 1965 y hasta 1974, cuando la Ley de Bosques fue sustituida por el D.L. 701.

Para describir el desarrollo histórico de las industrias de madera aserrada, pulpa (o celulosa), papel y otros derivados de productos forestales, sin duda la característica dominante del clima económico a lo largo de todo el período entre 1931 y 1973 fue "proteccionista", aunque en este contexto la protección brindada fue en contra de la competencia externa. Como parte integra de la estrategia de crecimiento hacia adentro seguida por gobiernos sucesivos, las industrias forestales gozaron de medidas fuertes y variadas de protección. Además de las exenciones tributarias de la Ley de Bosques para aquellas empresas nacionales que hicieron sus propias plantaciones, las importaciones de los productos forestales estaban sujetas a altos aranceles aduaneros. Por otro lado, aunque las importaciones de maquinaria y equipos también estaban sujetas nominalmente a aranceles, éstas gozaban de una serie de rebajas y franquicias, de acuerdo con el tipo de equipo y con la Región en la cual estaría instalado. Como resultado neto de esa estructura de aranceles diferenciados, la protección efectiva para estas industrias era aún más alta. Asi, en el primer trimestre de 1974, la tasa nominal de protección alcanzó al 116\% para productós de madera y muebles y el $128 \%$ para el papel y productos de papel; la prote 2 ción efectiva, en cambio, llegó a las tasas absurdas de $501 \%$ para productos de madera, $135 \%$ para muebles y $1.299 \%$ para papel y productos de papel (Aedo, C. y Lagos, L. F., 1984).

Más allá de la protección arancelaria, existían otros elementos de la política comercial que beneficiaban a las grandes empresas nacionales en desmedro directo de los dueños independientes de bosques. Se prohibia la exportación de cualquier tipo de madera en bruto y descortezada, y de los rollizos en general. Como si esto fuera poco, el Banco Central exigía la presentación de "Certificados de Origen y Calidad" antes de que se permitiera la exportación de cualquier clase de madera, lo cual le otorgaba a la autoridad la facultad efectiva de prohibir la exportación de madera de "baja calidad", como por ejemplo la madera aserrada de Pino Radiata. Por supuesto, al restringir, si no eliminar, la alternativa de exportar, el efecto neto de estas dos medidas fue el de otorgar un poder monopsónico absoluto a los pocos compradores grandes nacionales, esto es, a los productores de papel, pulpa y madera para aserrar.

Para completar el cuadro institucional que enfrentaban los particulares, cabe mencionar que, en el aspecto administrativo, toda decisión oficial respecto a cuestiones relaciona- 
das con el manejo del recurso forestal debía pasar por las manos de por lo menos una de las siguientes instituciones estatales: la Dirección de Bosques del Ministerio de Tierras y Colonización, el Departamento Forestal de la Dirección de Agricultura y Pesca del Ministerio de Agricultura, la División Forestal del SAG, la Corporación de Reforestación (COREF), el Instituto de Desarrollo Agropecuario y la CORFO. Finalmente, aunque durante los gobiernos de Frei y Allende no se llegó a expropiar plantaciones forestales, la existencia de la amenaza creciente de la reforma agraria sirvió como un elemento más en contra de la confianza necesaria para que el sector privado emprendiera las inversiones de largo plazo inherentes a la plantación forestal: mientras en 1970 el estado plantó directamente el $46 \%$ de las plantaciones totales del país, entre 1971 y 1973 dicho porcentaje subió al $78 \%$ y más del $91 \%$ en 1973, para volver a bajar al $46 \%$ en 1974 y paulatinamente al $15 \%$ en 1978 , y prácticamente a cero en los cuatro años siguientes (2).

Es interesante advertir que hasta mediados de la década de los cuarenta, cuando se iniciaron las industrias de celulosa, papel y cartones y tableros, la única industria forestal era la de madera aserrada. Bajo la protección que existía, en 1946 la Compañía Manufacturera de Papeles y Cartones produjo 34.000 toneladas de papeles y cartones (abasteciendo el $60 \%$ del consumo interno), producción que creció hasta 52.000 toneladas ( $80 \%$ del consumo interno) en 1954. Con financiamiento del Banco Mundial, en 1959 la CMPC inauguró su planta de celulosa al sulfato de Laja y en 1963 entró en funcionamiento su planta de celulosa y papel de periódico de Nacimiento (INFOR-CORFO, Octubre 1987, pág. 1).

Pero fue sólo en la década de los sesenta cuando se intentó generalizar el empuje hacia el desarrollo industrial del sector forestal, comenzando a mecanizarse los aserraderos e instalarse plantas nuevas de celulosa, papel periódico y tableros. Más aún, en 1965 el gobierno introdujo un plan nacional de forestación con Pino Radiata, con el objetivo de plantar 50.000 hectáreas por año en los años setenta. Como se ve en el Cuadro 1, aunque en 1970 sólo se logró plantar casi 30.500 hectáreas, es evidente que dicho plan condujo a (por lo menos coincidió con) un significativo aumento en el ritmo de plantaciones a partir de 1965.

También es cierto que entre 1965 y 1970 el sector industrial de productos forestales experimentó un crecimiento notable. Aunque la producción de madera aserrada estuvo más bien estancada, la producción de celulosa creció a la tasa anual del 10,3\% (18\% por año entre 1965 y 1969), la de papel para periódico a un $5 \%$ por año, otros papeles y cartones a casi un $11 \%$ ( $21 \%$ entre 1965 y 1969) y tableros y chapas a casi un $9 \%$ anual. Sin embargo, el desarrollo del sector en ese quinquenio también demuestra otra característica típica de la estrategia económica de la época: aún todos los incentivos enormes proporcionados a la industrialización de los productos basados en el recurso forestal -la protección arancelaria efectiva, la prohibición contra exportaciones de la materia prima, las exenciones tributarias, etc.- no bastaban, aparentemente, para que el sector privado por sí solo efectuara las inversiones conducentes a la mayor producción alcanzada. Más bien el sector creció por medio de una creciente participación directa del estado: en 1967, la CORFO se formalizó como propietaria del $60 \%$ de la planta de Celulosa Arauco; en 1969 INFORSA pasó a ser filial de CORFO; y en ese mismo año se firmó el contrato para la corstrucción de la planta de Celulosa Constitución, también filial de CORFO (INFOR-CORFO, Octubre 1987, pág. 1). Por lo visto, todavía faltaba algo para que las empresas privadas y protegidas asumieran el rol protagonista en el desarrollo del sector. Como se argumentará más adelante, ese elemento faltante no era el recurso forestal.

El Cuadro 3, por sur parte, confirma que aún con el desarrollo de la producción del sector forestal, ni el sector privado ni el público se dirigían hacia el mercado externo. Hasta antes de

(2) Ver Cuadro 1. 
los años sesenta, las únicas exportaciones eran de madera aserrada, mientras que se comenzó la exportación de celulosa, papel periódico y otros productos sólo en esa década. Hasta 1973, el total de las exportaciones forestales sobrepasó el $4 \%$ de las exportaciones totales del país únicamente en el año 1971.

En resumen, a lo largo del período bajo consideración en esta sección, junto con las ventajas naturales de Chile como productor forestal, el estado agregó una serie de incentivos y desincentivos a la actividad forestal y a las industrias basadas en el recurso forestal. El efecto neto fue un sistema con fuertes incentivos discriminatorios a favor de ciertos rubros del sector, las industrias de pulpa, papel y madera aserrada, y en contra del productor independiente del recurso primario en materia de la comercialización, factor discriminatorio que contrarrestaba, en alguna medida, los incentivos tributarios en favor de la plantación. La combinación final, junto con la participación estatal directa, claramente ayudó a la expansión observada en las distintas partes del sector forestal, aun cuando también está claro que no condujo a una maximización de la riqueza neta que el sector podría haber rendido para la economía chilena, ni siquiera en base al volumen del recurso forestal del que la economía disponía.

\section{EL DESARROLLO DEL SECTOR FORESTAL BAJO LAS POLITICAS FORESTALES Y ECONOMICAS DEL GOBIERNO MILITAR}

Desde su comienzo en 1973 el actual gobierno ha seguido una orientación en materia de política económica radicalmente distinta a la que caracterizó la conducción económica a lo largo de las décadas anteriores. A grandes rasgos, la nueva política instaurada tiene como fundamentos generales el derecho a la propiedad privada, una "economía de mercado" con la libre determinación de precios como mecanismo para asignar los recursos de la economía y el empuje del sector privado para generar el crecimiento económico, la apertura al comercio exterior para aprovechar las ventajas comparativas del país, y el principio de la subsidiariedad del estado, según el cual las actividades del estado se limitan sólo a aquellas áreas que no serían adecuadamente desarrolladas por la iniciativa privada.

El conjunto de medidas generales de política económica tomadas en consecuencia con esta nueva orientación ha ejercido impactos significativos sobre el desarrollo de todos y cada uno de los componentes del sector forestal chileno. Además, el gobierno ha introducido ciertas políticas específicas respecto al sector. Aunque sería quizás natural evaluar globalmente el desenvolvimiento del rubro forestal a lo largo de los últimos catorce años, para propósitos del presente artículo será más conveniente distinguir entre la actividad de la forestación propiamente tal, por un lado, y, por el otro, la evolución de la producción y las exportaciones de los productos forestales.

\section{La Política Forestal y el Desarrollo del Recurso}

Con el propósito de fomentar la forestación de las tierras aptas, asegurar la reforestación de bosques explotados, racionalizar los procesos de explotación y estimular el manejo óptimo del recurso, en Octubre de 1974 se oficializó el D.L. 701 de Fomento Forestal. Esta ley, para incentivar la forestación, estableció la absoluta inexpropiabilidad de los terrenos forestados, garantía indispensable después de las experiencias vividas bajo la reforma agraria, creó la bonificación del $75 \%$ tanto del costo de la forestación (de una sola vez por predio calificado como preferentemente forestal) subsidio que caducará en el año 1994, como de los costos de manejo $\mathrm{y}$ administración e introdujo algunas franquicias tributarias, bastante reducidas en relación, tan- 
to a las de la antigua Ley de Bosques como al valor de las bonificaciones del D.L. 701 (3). Además, entre 1975 y el mes de junio de 1979, el Banco Central mantuvo una línea de créditos para el fomento forestal, la cual fue aprovechada por intermedio del Banco del Estado y varios bancos privados. Dichos créditos tenían plazos de tres años, con uno de gracia, para compañias de pulpa y papel, y de seis años, tres de gracia, para personas naturales. La tasa de interés mínima exigida por el Banco Central era del $12 \%$ real anual, de hecho, las tasas cobradas a los tomadores de estos créditos fluctuaban entre el 14 y el $18 \%$ real anual. Los montos de crédito total otorgados fueron de (en millones de US\$) 2,4 en 1975; 2,5 en 1975-1976; 3,4 en 1976-1977; 6,2 en 1977-1978 y 12,2 en 1978-1979 (Aninat, Claro y Méndez, 1982, pág. 51).

En materia de preservación del recurso forestal renovable, la nueva ley exige, primero, que todos aquellos privados que se acogen a los beneficios de la ley presenten y cumplan con un plan de manejo para todas las etapas desde la forestación hasta la explotación del bosque. Segundo, se establece la obligatoriedad de replantar un número de hectáreas por lo menos igual al número explotado, haya o no recibido el predio involucrado cualquier beneficio otorgado por el D.L. 701. Finalmente, respecto a la institucionalidad del sector, el D.L. 701 consolida en un ente único (CONAF) todas las atribuciones necesarias para normar el desarrollo del sector y velar por el cumplimiento de las exigencias legales. Posteriormente, el D.L. 2565, de fecha 21 de Marzo de 1979, introdujo una serie de modificaciones al D.L. 701, con la finalidad principal de permitir la mayor incorporación de los predios de pequeños propietarios a la ley de fomento forestal.

El conjunto de estas tres piezas legislativas, todas consecuentes con la nueva orientación económica del actual gobierno -especialmente en cuanto al derecho de propiedad (de hecho, con la creación de propietarios) - fue acompañado por otras decisiones más bien administrativas que las complementaban, al traspasarse la ejecución de las actividades productivas a los agentes privados. CONAF, además de ir paulatinamente reduciendo sus esfuerzos en la plantación directa, licitó prácticamente todos sus activos forestales, sus tierras, más las de CORA, que se habian clasificado como preferentemente forestales, y todos sus viveros, implementos y herramientas. Siguiendo el mismo lineamiento, la CORFO licitó las empresas INFORSA, Forestal y Celulosa Arauco y Celco. Así, aunque el estado ha mantenido un rol importantísimo en el desarrollo del sector forestal, a través del subsidio, la exención tributaria y la reglamentación y control de las normas de preservación y reforestación, ha dejado de ser el actor directo en las actividades productivas.

La evaluación del impacto de la política forestal sólo puede realizarse en términos del desarrollo del recurso forestal y los costos que éste ha significado para el pais hasta la fecha. Por supuesto, a sólo catorce años desde su iniciación, estas políticas todavía no han comenzado a rendir sus beneficios concretos y contables. El Cuadro 1 presenta los datos más relevantes para dicha evaluación.

El primer hecho que salta a la vista es que en 1975, el primer af́o de vigencia de las provisiones del D.L. 701, se plantaron casi el doble de hectáreas que el área máxima plantada en cualquier año del "plan de forestación" de la década de los sesenta. Bajo el gobierno actual, se han plantado (hasta 1986) un total de 830.356 hectáreas de Pino Radiata, casi el $77 \%$ del stock existente en el país al final de ese último año. La plantación promedio anual desde la promulgación del D.L. 701, 60.865 hectáreas, es tres veces el promedio anual de plantaciones entre los años 1960 y 1973.

(3) Se recordará que el único incentivo en la Ley de Bosque fue una generosa exención tributaria. Con el D.L., en cambio, Aninat, Claro y Méndez (Op. cit., pág. 68) encuentran que las franquicias tributarias son mucho menos importantes que la bonificación para la plantación y la posterior mantención de los predios forestales. 
El segundo hecho importante ha sido la respuesta del sector privado. Ya en 1974, antes de D.L. 701, las plantaciones privadas repuntaron en un factor de 7,3 en relación a su nivel del último año de la UP, demostrando el impacto de la seguridad respecto al recién reestablecido derecho a la propiedad privada. En seguida, se nota la creciente importancia del sector privado en las plantaciones totales, de acuerdo con la política de CONAF de ir eliminando sus plantaciones directas. De hecho, entre 1979 y 1982 la CONAF plantó menos que el 0,3\% del total planteado en esos cuatro años. Entre 1983 y 1985, su actividad volvió a subir, en respuesta a la necesidad social de proveer fuentes de trabajo durante la aguda recesión que el pais sufría, para después cesar sus plantaciones directas por completo en 1986.

Con el D.L. 701, el sector privado ha plantado hasta 1987, 625.931 hectáreas de Pino Radiata, el $79 \%$ de las plantaciones totales realizadas en el pais. Con todos los beneficios de la nueva legislación, los privados plantaron un promedio de 52.160 hectáreas por año, más de dos y media veces el ritmo de plantaciones totales entre 1960 y 1973 . Pero quizás lo más impresionante de todas las cifras del Cuadro 1 es el hecho de que en estos mismos doce años, el sector privado ha plantado un promedio anual de 17.235 hectáreas sin bonificación alguna, un $50 \%$ más que el promedio anual total bajo la antigua Ley de Bosques. Las razones detrás de este último fenómeno incluirán, seguramente, la exigencia de reforestación, uno de los aspectos más destacables del D.L. 701. Pero no es menos cierto que las medidas más generales de la politica económica (tratadas en la siguiente sección del presente artículo) han permitido que las ventajas naturales inherentes a la forestación en Chile se hayan traducido en el incentivo económico natural que es propio de las rentabilidades altas que pueden obtenerse de los productos forestales. Este incentivo económico, junto con el derecho garantizado de la propiedad privada, ha servido como otro estímulo indirecto a la forestación no bonificada que se observa en los últimos años.

Ahora bien, no es ninguna sorpresa que los agentes económicos respondan frente a un incentivo beneficioso, siempre que tengan confianza en la continuación de las políticas y en el respeto por su derecho de propiedad. Por eso, la próxima pregunta que debería investigarse es el tamaño del costo fiscal de las plantaciones bonificadas. De acuerdo con datos de CONAF, entre 1976 y 1986 (para las plantaciones acogidas al D.L. 701 y efectuadas entre 1975 y 1985), el monto total de las bonificaciones para la plantación y la administración posterior asciende a US\$ 65,7 millones, o sea casi seis millones de dólares por año. Estas bonificaciones, capitalizadas al final del año 1987 a la tasa LIBO, alcanzarían el valor de US\$ 125,6 millones.

Aunque dicha suma no es despreciable, debe ser comparada con algún otro valor para que pueda ser evaluada. Con ese propósito, considérense los costos involucrados en la inversión de plantar, administrar y manejar una hectárea de Pino Radiata. El estudio del Banco Mundial (Banco Mundial, 1986) presenta una estimación detallada de estos costos, año por año desde la plantación hasta el momento de la corta, tal como lo indica el Cuadro 4 (el cálculo del estudio referido sigue hasta el año 24; aquí, como han pasado sólo catorce años desde 1974, se corta el cuadro a dicho número de años). Aplicando estas estimaciones de costos, una hectárea plantada en 1974 tendría un costo total invertido igual a la suma del costo en cada uno de los catorce años, USS 817,32 al final de 1987, sin incluir costos de interés, y de US\$1.877,57 si se capitaliza el flujo a la tasa LIBO. Una hectárea plantada en 1975 tendría un costo igual a la suma de los valores de sólo los primeros trece años; y así sucesivamente (4).

(4) Los distintos valores del costo de inversión total presentados a continuación en el texto suponen que todas las plantaciones han sido manejadas con raleos en los años 5 y 12 y podas en los años 7,9 y 11 . Obviamente, pueden observarse varios patrones de manejo (o ningún manejo) que arrojarían costos diferentes. Sin embargo, si sólo la mitad de las plantaciones fueran manejadas, el costo total de inversión para el país sería reducido en un máximo de $10 \%$. 
Dadas estas estimaciones del costo de inversión por hectárea de Pino Radiata, se puede calcular que entre 1974 y 1987 las plantaciones privadas habrian significado para el pais -o sea, los gastos netos privados más el costo fiscal de las bonificaciones - una inversión total de US\$ 326,3 millones, sin incluir concepto alguno de interés, o US\$ 577,5 millones capitalizando estos flujos en la tasa LIBO. De estos volúmenes de inversión, el total de las bonificaciones representa el $20,1 \%$ sin intereses o el $20,3 \%$ capitalizando a LIBOR. Es más, aquellos privados que plantaron sin bonificación alguna habrán invertido, bajo el mismo concepto, un total de USS 117,9 millones (un gasto $80 \%$ mayor que el total de las bonificaciones), sin intereses, o US\$ 222,8 millones capitalizando a LIBOR. Por lo tanto, aunque el esfuerzo fiscal en el financiamiento de los bosques de Pino Radiata ha sido importante, el esfuerzo del sector privado ha sido unas cuatro veces mayor. Finalmente, siempre aplicando estas mismas estimaciones de costos anuales, se deduce que la economia en su conjunto -las plantaciones privadas más las del sector público- ha invertido la suma de US\$ 429,3 millones sin intereses, o bien US\$768 millones incluyendo sólo la tasa LIBO como la tasa alternativa de interés a lo largo de estos catorce años, una inversión que equivale a más del $4 \%$ de la deuda externa total del pais al final de 1987 (US\$ 19.099 millones).

Debe recordarse que hasta la fecha esta inversión en el recurso forestal no ha brindado prácticamente nada del retorno que promete rendir para el pais en el futuro, y que es potencialmente de una gran magnitud. Para especular en los términos más simplistas, basta recordar que se ha proyectado que la disponibilidad total de madera de Pino Radiata será en 1995 un 56\% mayor que su nivel de 1987 (Subcomisión de Inversiones Forestales, Mayo 1987, pág. 13). Si se mantuvieran constantes en sus niveles de 1987 el grado de aprovechamiento de ese stock de madera, la composición porcentual de productos y de exporaciones/importaciones, y los precios mundiales de estos productos, entonces en 1995 se exportaría un monto de US\$ 900,6 millones de productos forestales. El aumento de divisas, en relación a 1987, sería de USS 323,3 millones. Por otro lado, el costo total de la bonificación otorgada hasta 1986 tendria un valor capitalizado de USS 250,3 millones en 1995 , si la LIBOR es constante e igual al $9 \%$ por año entre 1988 y 1995. Por lo tanto, el aumento de divisas en sólo un año (1995) bastaria para pagar el $130 \%$ del costo fiscal capitalizado del subsidio forestal, mientras que el mismo aumento de divisas en dos años seguidos podria pagar el $258 \%$ de dicho costo. Desde este único punto de vista demasiado simplista, pero sin duda pesimista, pareciera que los recursos dedicados a las bonificaciones forestales terminarán habiendo sido una inversión extremadamente rentable para Chile.

Finalmente, considérese el grado de éxito registrado frente a la meta gubernamental de crear más y nuevos propietarios y difundir la propiedad más ampliamente entre la población. Aunque no se dispone de la información necesaria para examinar los cambios en la estructura de la propiedad forestal, las cifras señalan que al final de 1985 casi la mitad de las hectáreas plantadas de Pino Radiata pertencia a propietarios pequeños (INFOR-CORFO, Octubre 1986, pág. 18). El hecho de que este grupo de unos 5.000 propietarios, cada uno con un predio de aproximadamente 100 hectáreas en promedio, posea más hectáreas de plantaciones que la CMPC, INFORSA y Celulosa Arauco en su conjunto, indicaria un relativo éxito con respecto a esta meta.

En resumen, ya se ha visto que bajo la política de forestación actual se ha logrado un enorme aumento en la superficie de plantaciones de Pino Radiata, conseguido mayoritariamente por el sector privado; que el costo de los subsidios ha sido una suma importante en términos absolutos, pero pequeña en comparación con los volúmenes potenciales de exportaciones que el pais podría percibir en el futuro; y que la propiedad de las plantaciones se ha desconcentrado en una medida importante. Queda una última cuestión que debería ser tratada. Esta es la justificación y "necesidad" del subsidio mismo. De acuerdo con el principio de la subsidiariedad, el 
estado debería intervenir solamente en aquellas actividades que, por la naturaleza y circunstancias del caso, el sector privado no emprendería, o no las realizaria en el nivel óptimo desde el punto de vista de la economía nacional. Respecto a la bonificación forestal, entonces, la duda que habria que intentar aclarar es si existian o no factores que hubieran podido impedir que el sector privado forestara al ritmo requerido para alcanzar el óptimo social, de no existir tal bonificación.

$\mathrm{La}$ interrogante es extremadamente difícil de responder en forma satisfactoria. Un primer indicador consistiría en evaluar la rentabilidad del "proyecto" forestal, desde el punto de vista privado, con y sin los beneficios del D.L. 701. Existen dos estudios al respecto, con resul. tados opuestos. Primero, en su informe de fecha agosto de 1982 los consultores Aninat, Claro y Méndez afirman que, sin los beneficios de la ley, la actividad de forestación no sería rentable, a una tasa de descuento del $10 \%$, en ninguna de las regiones investigadas; con los subsidios y los beneficios tributarios, en cambio, si lo sería. Sin embargo, estos autores señalan al mismo tiempo que, de producirse un aumento real del precio de venta del $21 \%$, la actividad sería privadamente rentable aún sin el D.L. 701. De hecho, la evolución de los precios entre 1982 y 1986 ha mostrado que el precio del bosque en pie (pesos por $\mathrm{m}^{3}$ ) habria aumentado en más del $50 \%$ (INFOR-CORFO, Junio 1987, pág. 82). El segundo estudio, del Banco Mundial de Agosto de 1986, presenta resultados para distintas ramas industriales de productos de madera que permiten inferir que, aún sin el subsidio del D.L. 701, la forestación sería una actividad rentable a una tasa de descuento del $10 \%$.

Un segundo indicador numérico consiste en la rentabilidad social del proyecto de forestación, la cual fue también calculada en el estudio de Aninat, Claro y Méndez. Ajustando los parámetros privados por sus valores sociales, ellos encontraron que en todas las regiones (con excepción de las tierras arenales) la forestación era rentable desde el punto de vista social, incluyendo todos los costos de vigilancia, control y administración en que incurría el estado para aplicar el D.L. 701. La diferencia con respecto a los resultados privados se debe al mayor valor social de las divisas y especialmente al menor costo social de la mano de obra no calificada que se emplea en las etapas de forestación, poda y raleo. El aumento real observa. do en los precios durante los últimos años obviamente magnifica esta rentabilidad social.

Los indicadores anteriores no son concluyentes. Aunque no pareciera caber duda respecto a la rentabilidad social de la forestación, no está claro que se requiera de los beneficios estatales para inducir la participación del sector privado, si bien es notoria la sensibilidad de la rentabilidad privada al precio de la madera puesta en el bosque. Así, surge la incógnita de si no habría otras razones que justifican la intervención estatal para incentivar un mayor nivel de plantación. La justificación clásica sería la existencia de externalidades positivas que el privado no puede captar, lo cual daría por resultado un ritmo de plantación privado menor que el óptimo social. De hecho, el estudio de Aninat, Claro y Méndez señaló varias fuentes de este tipo de externalidad, con énfasis en los aspectos ecológicos. En efecto, la existencia de la vegetación forestal ayuda directamente en la preservación de los suelos, su humedad y fertilidad. Otros efectos dicen relación con los beneficios de la belleza escénica, la protección de la vida silvestre y otros.

En adición a tales efectos reales, aunque no cuantificables, en Chile existía otra especie de externalidad que sin duda incidia significativamente en las decisiones de los agentes económicos. La inversión forestal es naturalmente de muy largo plazo, con fuertes costos al principio y los ingresos correspondientes sólo al final de una espera de entre 18 y 26 ó 30 años. La dificultad de predecir beneficios tan lejos en el futuro sirve para sí sola como un desincentivo a tal tipo de inversión, en relación a las de más corto plazo. $\mathrm{Si}$ a este factor se agrega el contexto histórico político, en el cual no existía ninguna estabilidad en las reglas fundamentales del juego - derecho de propiedad, sistema económico, etc.- obviamente se multiplican los desincentivos en contra de inversiones del largo plazo. Así, el efecto neto de esta falta de claridad y estabili- 
dad equivale a una externalidad que debe superarse para que se desarrolle el recurso forestal, lo cual si es socialmente beneficioso. El estado podría o plantar directamente o bien estimular la plantación privada a través de algún esquema de subsidios.

No obstante su validez, los argumentos anteriores no constituyen, ni siquiera en su conjunto, un caso inequívoco en favor de los estímulos fiscales vigentes para la plantación forestal a lo largo de los últimos 57 años y, por consiguiente, simplemente no existe ninguna evidencia empírica que permita evaluar económicamente los niveles alternativos de los incentivos que de hecho han sido otorgados. Aunque sea cierto que el subsidio se paga solo, con mayores ingresos de divisas, o bien que la forestación tiene una rentabilidad social positiva y mayor que la priva$\mathrm{da}$, sin duda se encontraría lo mismo en otros sectores de la economía, y no hay nada que garantice que el sector forestal tenga una prioridad objetiva dentro de ellos. De la misma manera, la externalidad innegable que se debía a la incertidumbre respecto a la estabilidad de las reglas de juego económicas afectaba por igual a toda la inversión de mediano o largo plazo, no sólo a la del sector forestal.

Dejando de lado, por lo tanto, esta ambigüedad respecto a la justificación de incentivar la plantación forestal, debe señalarse que el D.L. 701, a diferencia de la antigua Ley de Bosques, garantiza la perpetuación del bosque al exigir la reforestación, lo cual representa un beneficio social adicional que los inversionistas privados no considerarian en su totalidad. Además, al subsidiar la forestación en todas sus etapas, en vez de beneficiar a los agentes privados sólo al final del ciclo forestal mediante exenciones tributarias, el D.L. 701 ha permitido que los dueños de predios pequeños, que no tenían acceso al financiamiento de largo plazo ni manera alguna de salirse del sector a través de un mercado secundario para campos forestales, pudieran efectivamente acogerse a los beneficios fiscales disponibles y por tanto participar en el sector. Más aún, al bonificar también la administración y el manejo del bosque, se va a cosechar en Chile madera de Pino Radiata de mayor calidad y mayor precio de venta, aún para los propietarios pequeños, que quizás no hubieran podido de otra manera financiar los gastos involucrados en el manejo del bosque.

Muy relacionado con lo anterior está un argumento de tipo distributivo. El subsidio genera una tendencia al alza del precio de los terrenos aptos para forestar; de hecho, algunos ejecutivos de las empresas más grandes del sector afirman que ése sería el mayor efecto de la bonificación. En la medida en que eso es así, los subsidios del D.L. 701 representarían una manera por la cual los beneficios económicos de la actividad forestal llegan a los pequeños propietarios. Este razonamiento es respaldado por el hecho de que sólo los terrenos clasificados como "preferentemente forestales" pueden acogerse al D.L. 701. Asi, los predios que no tienen un claro uso alternativo, y por tanto alcanzarían un precio de venta muy reducido, pueden obtener ahora precios que reflejan, al menos parcialmente, el subsidio forestal.

\section{LA POLITICA ECONOMICA Y EL APROVECHAMIENTO DEL RECURSO FORESTAL}

Si bien es cierto que la existencia de una masa de recurso forestal es indispensable para alimentar el desarrollo de industrias de productos como madera aserrada, celulosa, papel y otros derivados, es igualmente claro que la mera presencia del recurso no basta. También se requiere de un conjunto de políticas económicas que propendan a la explotación y utilización racional del recurso. Tal como se ha señalado anteriormente, el significativo crecimiento experimentado por el sector entre 1930 y 1973 se limitó a industrias que estaban fuertemente protegidas y que mostraban escaso interés por los mercados externos. Con tal ausencia de competencia externa, estas industrias podian crecer sin preocuparse de utilizar el recurso forestal eficientemente. 
La evolución de la producción y las exportaciones desde 1974 hasta 1987 se puede apreciar en los Cuadros 2 y 3. El primer hecho llamativo del Cuadro 2 es la fuerte recuperación en la producción de casi todos los sectores, tanto en relación a 1973 como en relación al promedio entre 1965 y 1973. En cuanto al extraordinario crecimiento que registran las exportaciones forestales, basta señalar que mientras la producción del sector creció un $60 \%$ más rápido que el PGB, las exportaciones de madera, celulosa, papel y otros derivados crecieron un $250 \%$ más rápido que las exportaciones totales del país. Entre 1974 y 1987, mientras el país aumentó sus exportaciones en un $143 \%$, el sector forestal lo hizo en un $355 \%$. Este auge afectó a todos los productos tradicionales (salvo la cartulina para tarjetas perforadas) e incluso emergieron una serie de nuevos productos de exportación (ver Cuadro 7).

Al intentar explicar esta evolución de la producción y, especialmente, las exportaciones de productos forestales, quizás convenga comenzar por reconocer un hecho innegable. Se ha argumentado en algunos círculos que las exportaciones de los últimos años provienen de árboles que ya se habían plantado antes de la introducción de las políticas económicas del gobierno astual y efectivamente eso es así. Las plantaciones realizadas bajo el D.L. 701 comenzarán a proveer materia prima para la celulosa de ahora en adelante, mientras que todavía faltan unos cinco a diez años antes de que dichas plantaciones comiencen a alimentar a la industria del aserrío.

Pero la disponibilidad del recurso forestal es sólo un problema. Otro problema es el grado al cual el recurso sea aprovechado por la economía del país y resulta evidente que ese aprovechamiento ha sido significativamente mayor desde 1974 en adelante que en los años sesenta. La información que respalda esta conclusión se completa con el Cuadro 5, que muestra la distribución por edad del stock de Pino Radiata en 1965, 1980 y 1986 (5). Allí se ve que el stock disponible de madera en pie que sirve para la producción de madera aserrada (árboles con por lo menos 21 años) fue calculado en 32.319 hectáreas, 91.752 hectáreas y 70.871 hectáreas para esos tres años respectivamente. Así, el stock aprovechable para este producto en 1980 fue 2,84 veces mayor que en 1965, mientras en 1986 fue 2,19 veces mayor que en 1965 .

Por otro lado, sabiendo que en promedio cada $\mathrm{m}^{3}$ de madera aserrada de Pino Radiata requiere de $2,09 \mathrm{~m}^{3}$ de madera aserrable, se deduce de las cifras del Cuadro 2 que entre $1965 \mathrm{y}$ 1969 se cosechó un promedio anual de 1,10 millones de $\mathrm{m}^{3}$ de madera aserrable proveniente de bosques plantados en el año 1945 y antes. En ese quinquenio, el año de mayor producción fue 1966, con 1,21 millones de $\mathrm{m}^{3}$. En cambio, con el stock de hectáreas de Pino Radiata de 1980 (árboles plantados en el año 1960 y antes), entre 1980 y 1984 la producción de madera aserrada, más las exportaciones de trozos de madera aserrable (Cuadro 7), requirió una cosecha anual promedio de 3,98 millones de $\mathrm{m}^{3}$, y este promedio incluye el impacto fuerte y negativo de la recesión sufrida durante ese quinquenio.

Así, mientras que el stock de plantaciones en edad de proporcionar madera aserrable fue 2,84 veces mayor en 1980 que en 1965 , la producción aumentó en 3,61 veces; en el período 1980-1984 el grado de aprovechamiento fue un 27\% mayor, en promedio, que en el período 1965-1969. Desde 1980, incluso, este grado promedio de aprovechamiento ha excedido en $16 \%$ el nivel alcanzado en 1966, el año de mayor producción en la segunda mitad de los sesenta.

Si se hace ese mismo tipo de comparación, utilizando el stock potencial del año 1986 y la producción de madera aserrable en 1985 y 1986, se ve que en estos últimos dos años la producción media excedió en 4,47 veces la del período 1965-1969, con un stock de hectáreas disponible 2,19 veces mayor, lo cual indica un aumento en el grado de aprovechamiento del $104 \%$ en relación a ese quinquenio y de $86 \%$ en relación al año 1966. Aunque se podrían criticar los

(5) El lector recordará la discusión anterior respecto al problema de la consecuencia entre estas cifras y las de las plantaciones anuales. Para 1980, las estimaciones del stock de hectáreas con 21 y más años de edad parecieran ser infladas. 
periodos de comparación o cuestionar la precisión de las cifras del stock disponible del recurso, difícilmente podría encontrarse una comparación entre dos años (salvo quizás el peor año de recesión en los ochenta con el mejor año anterior a 1974) que cambiara la conclusión de que desde 1974 el pais ha logrado utilizar más intensamente su recurso forestal. ¿Cuál sería la explicación de este mayor aprovechamiento y del mayor crecimiento de la producción y de las exportaciones en el segundo período en relación al desarrollo del sector bajo las políticas económicas vigentes entre 1960 y 1973 ?

Hay dos conjuntos de medidas económicas que, a nuestro juicio, explican la favorable evolución del sector durante los últimos catorce años: 1) las políticas de apertura al comercio internacional y 2) las políticas respecto a los puertos y el transporte marítimo.

Una de las primeras innovaciones de política económica del gobierno actual fue la apertura al comercio internacional, eliminando toda traba cuantitativa a la importación y, a partir de 1974 , rebajando y uniformando los niveles arancelarios que protegían la producción nacional competitiva con las importaciones. Este proceso culminó en 1979 con el establecimiento de un arancel uniforme (con pocas excepciones, especialmente el sector automotriz) del $10 \%$. El hecho de que esta rebaja arancelaria tuviera como uno de sus efectos el fomento de las exportaciones forestales, y por tanto, de la explotación de los bosques, tiene dos fundamentos explicativos.

Primero, una de las lecciones más inequívocas de los principios de la teoría económica enseña que las trabas que nominalmente actúan en contra de las importaciones, constituyen de hecho restricciones al comercio externo del país, importaciones y exportaciones. Es decir, el impuesto a las importaciones se transforma sólo parcialmente en una verdadera protección para los productores nacionales de bienes importables, mientras que el resto de dicho impuesto se transforma en un impuesto en contra de las exportaciones del país. Para Chile, se ha demostrado empíricamente (Sjaastad, L.A., 1981) que un 55\% de la protección arancelaria nominal se transforma de hecho en un impuesto a las exportaciones. Sjaatad señala que, por sus efectos sobre los precios relativos, las barreras contra la importación vigente en 1970 equivalían a un arancel uniforme del $27 \%$, junto con un impuesto uniforme en las exportaciones del 33\%. Como el arancel promedio en el primer semestre de 1974 fue del 105\% (Cauas, J. y De la Cuadra, S., 1981) y la reforma arancelaria lo rebajó paulatinamente al $10 \%$ en 1979 , ese mismo proceso rebajó el impuesto implícito a las exportaciones, desde aproximadamente el $57 \%$ a solamente el 5,5\%. El impacto incentivador a favor de las exportaciones es evidente.

Segundo. De la Cuadra y Hachette (De la Cuadra, S. y Hachette D., diciembre, 1986) detectaron e intentaron estimar empíricamente un efecto dinámico en la oferta del sector manufacturero hacia un mayor nivel de eficiencia. En otras palabras, debido a la reforma arancelaria, aunque los sectores protegidos anteriormente sufrieron un efecto de precio negativo, simultáneamente para sobrevivir tuvieron que adecuar sus procesos productivos para poder enfrentar la competencia externa. Al nivel sectorial, esto puede haberse logrado mediante la entrada y salida de distintos empresas, por la incorporación de nuevas tecnologías, o por otros medios. Durante el período de la reforma arancelaria (hasta 1979), el sector que exhibió el mayor efecto dinámico fue "muebles" (de madera), el segundo fue "madera y productos de madera" y el tercero fue "pulpa y papel".

El hecho de que las industrias basadas en el recurso forestal se ajustaran tan bien a la apertura de la economía quizás puede explicarse por su traslado relativamente fácil hacia el mercado externo. Así, mientras que entre 1960 y 1974 el $91 \%$ de la producción de madera aserrada se destinaba al consumo interno y sólo el $9 \%$ a la exportación, entre 1975 y 1986 la participación de las exportaciones aumentó al $46 \%$. De la misma manera, la fracción de celulosa exportada aumentó desde ei $28 \%$ entre 1960 y 1974 hasta el 60\% entre 1975 y 1986. Finalmente, es necesario notar que este cambio en la estructura de las ventas tuvo lugar sin que el volumen de la producción nacional dedicada al consumo interno cayera. Evidentemen- 
te, estas industrias enfrentaron en forma exitosa el desafío de la competencia externa, lo cual constituiría otro indicador de las ventajas comparativas del sector forestal en Chile. Como todas utilizan al recurso forestal prácticamente en proporciones fijas, su crecimiento en los últimos catorce años se ha traducido en un aumento de la demanda por el bosque en pie, haciendo crecer su explotación y los ingresos para sus propietarios.

Simultáneamente con la reforma arancelaria, el gobierno también eliminó las trabas que existían en contra de la exportación de ciertos productos forestales. Con el Decreto Supremo $\mathrm{N}^{\circ} 259$ de julio de 1975 , se estableció la libertad absoluta de exportaciôn de todo producto forestal, en cualquier etapa de procesamiento, incluyendo troncos, astillas, madera aserrada o celulosa (se mantuvo, sin embargo, la prohibición total de explotar la Araucaria). A la vez, el Banco Central derogó el requisito de certificados de origen y calidad para poder exportar, junto con las "contingencias de exportación". Por supuesto, el efecto inmediato fue la eliminación del poder monopsónico que poseían las grandes empresas industriales del sector y el mejoramiento de los precios recibidos por los pequeños propietarios de bosques.

El impacto de estas medidas en el aprovechamiento del recurso forestal fue importante y rápido. Se presentan datos indicativos en el Cuadro $\mathrm{N}^{\circ} 6$, donde puede observarse que después de la recesión de 1975, el consumo de trozos de Pino Radiata, como insumo para las industrias tradicionals, creció fuertemente a pesar de la rebaja de la protección arancelaria y la eliminación del poder monopsónico. Por lo tanto, la exportación más intensiva del bosque, tal como se demostró anteriormente. La utilización total de madera en trozos aumentó en $91 \%$ entre 1974 y 1979 , mientras que la exportación de trozos creció desde el $0,1 \%$ de ese total en 1975 al $3 \%$ en $1977,10 \%$ en 1978 y $11,6 \%$ en 1979 (porcentaje que prácticamente se ha mantenido hasta 1986).

Un tercer aspecto de la orientación hacia el comercio exterior se refiere a la política cambiaria. Aunque ya en 1981, casi todas las exportaciones forestales habian disminuido, es importante advertir que la mayor caída ocurrió en los rubros madera aserrada y madera en trozos, y la explicación predominante de esa caída fue un problema político que surgió con la República Argentina en 1981, con lo cual ese país efectivamente cerró sus fronteras frente a las exportaciones chilenas. Así, tomando en cuenta ese problema de causa no económica, no hay evidencia clara de que la disminución del tipo de cambio real entre 1979 y 1982 perjudicara mayormente los volúmenes exportados de productos forestales. Más bien, el punto bajo para el sector coincidió con el peor año de la recesión mundial.

A raíz de esa "recesión de la deuda", y después de varios meses de vacilación e incertidumbre respecto a las políticas fiscal, cambiaria y arancelaria, a comienzos de 1985 el gobierno optó por un conjunto de políticas económicas consecuentes con el endeudamiento del país, la mantención de la estabilidad macroeconómica y el fomento de las exportaciones en general, principalmente a través de un tipo de cambio real alto. Esta nueva política, el llamado "ajuste estructural", junto con la mantención de aranceles bajos (aunque a niveles mayores que el $10 \%$ anterior) y parejos y la falta de trabas a la exportación, ha sido sin lugar a dudas un elemento fundamental en la recuperación de las exportaciones tradicionales de productos forestales, así como en la incorporación de los otros productos nuevos de exportación.

Finalmente, dentro de este primer conjunto de políticas aperturistas, la legislación respecto a la inversión extranjera ha tenido y seguirá teniendo, al menos por lo que indican los hechos ocurridos en los últimos meses, una importancia crucial para el desarrollo industrial del sector forestal. Confiando en las provisiones del D.L. 600, inversionistas extranjeros han estado incursionando en las distintas ramas del sector a lo largo de la última década. Especialmente destacada ha sido la cooperación técnica brindada por los neozelandeses, además de sus inversiones directas. En los dos últimos años, debido a los mecanismos de capitalización de la deuda externa, la participación de empresas extranjeras ha experimentado un auge espectacular. 


\section{INSTITUTO FORESTAL}

\section{WISECARVER Y S. TARDONES M.}

Para apreciar el orden de magnitud de esta actividad, considérense primero algunas de las proyecciones que se han preparado sobre las necesidades de inversión para el desarrollo futuro del sector forestal chileno. En el estudio del Banco mundial (Banco Mundial, 1986) se estimó que entre 1985 y el año 2000, la inversión requerida ascendería a los US\$ 2.500 millones. Parte importante de ese esfuerzo sería dedicado a la expansión de la capacidad de producción de celulosa. Asimismo, en un estudio del año 1985, cuando el país recién había comenzado a salir de la recesión, Lüders proyectó que las inversiones en plantas de pulpa serían "de tal envergadura que aún un sector privado chileno sano no las podrian haber financiado en el breve plazo presupuestado (1985-1995), sin la cooperación del capital extranjero o del Estado". (Lüders R., Marzo 1985). Sin embargo, con la decidida participación de empresas extranjeras, ya están en marcha y financiadas inversiones (exclusivamente del sector privado) en plantas de celulosa que representan un crecimiento anual en capacidad que excede en un $50 \%$ del ritmo proyectado por el Banco Mundial y que permitirán disponer en 1992 de una capacidad instalada adicional un $40 \%$ mayor que la proyectada en el estudio de Lüders.

El segundo conjunto de políticas que ha tenido especial incidencia en el crecimiento explosivo de las exportaciones forestales se refiere a las reformas efectuadas en todos los aspectos operativos de los puertos marítimos del país. Primero, en 1980 se aprobó la legislación que eliminó (salvo en casos de reciprocidad) la reserva de carga para la marina mercante chilena. Esta medida, junto con decisiones administrativas respecto a la exigencia de emplear únicamente tripulaciones chilenas, permitió a los exportadores chilenos un acceso a nuevas alternativas para la contratación del transporte marítimo, lo cual, al debilitar los poderes monopólicos que antes habian regido en la prestación de este servicio, tuvo el efecto netc de rebajar los costos promedios del flete marítimo.

Segundo, y en la práctica mucho más importante, a partir de 1979 se comenzó a abrir las operaciones de embarque y desembarque en los puertos públicos del país, junto con las inversiones correspondientes, a los interesados del sector privado. Además, en 1981 se rompió el fuerte monopolio que pose ían los estibadores, al eliminar como requisito para trabajar en los puertos la tarjeta de identificación del estibador (Wisecarver. D., 1986). Estos pasos, más el cambio que permitió el trabajo portuario durante los tres turnos (en vez de uno y medio, con el medio turno a un costo doble o mayor aún) han tenido impactos muy considerables en el rendimiento en los puertos y en el costo de embarque, tal como se puede apreciar en el Cuadro 8, efectos que evidentemente constituyen un factor más que ayuda a explicar el surgimiento del sector forestal como un generador de divisas para el país.

\section{CONCLUSION Y PERSPECTIVAS PARA EL FUTURO}

Toda estimación del potencial futuro del sector forestal debe partir de la disponibilidad del recurso, y determinar la magnitud de este parámetro podría parecer un ejercicio relativamente fácil, ya que actualmente se conoce el volumen de las plantaciones y las características del manejo. Por eso, estimar la oferta que habrá en 20 años más, dentro de ciertos rangos, pareciera ser una especie de cálculo mecánico. Sin embargo, como lo que interesa es la oferta flujo en el tiempo, dicha proyección no es tan fácil, puesto que influyen en ella una serie de factores físicos y económicos, incluyendo la tasa futura de plantación, el tipo de manejo, la evolución de la demanda por los distintos productos y, por tanto, el período de rotación, etc.

Existen varios estudios que han pretendido proyectar la disponibilidad futura del recurso forestal y los productos derivados. Quizás el más completo es "Disponibilidad de madera de Pino Radiata en Chile, 1986-2015", preparado por la Subcomisión de Inversiones Forestales. Esta proyección concluye que, en base a una tasa supuesta de plantación de 57.000 hectáreas por año y una rotación mínima de 20 años, "la disponibilidad total de madera experimentará 
un lento crecimiento en el próximo sexenio y después crecerá fuertemente hasta duplicarse a fines de siglo, para terminar triplicándose al final del período de proyección (6). Aunque otros estudios llegan a resultados que difieren en detalle, las órdenes de magnitud de la oferta total en el largo plazo siempre giran en torno al triple de la oferta total actual (Banco Mundial, 1986, pág. 15).

Respecto a la distribución de los productos finales que se producirían y a los volúmenes que serían exportados, las proyecciones se complican enormemente, debido a la proliferación de distintas variables que habría que tomar en cuenta. Por eso, el intento de especificar volúmenes $o$, por ejemplo, ingresos futuros de divisas sería poco más que un ejercicio especulativo. Lo que si se puede afirmar es que, independientemente de la importancia del sector forestal para el pais, a nivel mundial Chile nunca llegará a tener un tamaño suficiente como para influir en el precio de los productos tradicionales, estándares o poco elaborados de exportación, tales como trozos para aserrar, madera aserrada para embalajes, madera pulpable, pulpa química y papel para periódicos. Esta afirmación se basa en el hecho de que las exportaciones forestales de Chile constituyen tan sólo el $2 \%$ del comercio mundial de productos forestales. Por lo tanto, aún suponiendo valores excesivamente pequeños para la elasticidad-precio tanto de la demanda mundial por estos productos como de su oferta de parte de los países competidores, se puede demostrar que Chile será un tomador de precios, sea cual sea el volumen de sus exportaciones en el futuro previsible. En cambio, en la medida en que el país siga explorando productos no tradicionales y/o logre que el Pino Radiata sea aceptado como madera apta para la construcción y otros usos más "nobles", el rendimiento económico del recurso aumentará en relación a la alternativa de confiar en los productos tradicionales. En tales productos específicos, la cuestión de un eventual poder de mercado no puede descartarse.

Por otro lado, aún para cualquier caso base, dadas las plantaciones ya existentes, todos los análisis serios del desarrollo futuro del sector han enfatizado el hecho de que se requerirá un volumen apreciable de nuevas inversiones en equipos de extracción y plantas de procesamiento. Tal como se señaló en la sección anterior, inversionistas nacionales y extranjeros, han anunciado sus intenciones de comenzar varios de los proyectos requeridos, y el estado está investigando activamente la oportunidad de emprender nuevas inversiones complementarias de infraestructura. Sólo con el paso del tiempo se averiguará si se mantienen las condiciones y la confianza necesaria para que los agentes privados lleven a cabo los restantes proyectos para permitir el pleno y económico aprovechamiento del recurso que sí va a estar disponible.

Este último comentario es parte íntegra de la conclusión del presente análisis. La política forestal se ha mostrado altamente efectiva en conducir a un enorme crecimiento en el volumen del recurso forestal, pero la mera existencia del recurso no basta para realizar su potencial contribución a la riqueza del país. Para ello, también se requiere de todo un conjunto de otras políticas económicas que permitan que el recurso sea aprovechado de la manera más completa y más económica que sea consecuente con las demás condiciones del país. Las políticas de apertura al comercio exterior y de eficiencia en la operación de los puertos, y la garantía de derecho de propiedad, han probado ser eficaces hasta la fecha en el fomento de la producción de los bienes derivados del bosque chileno, y por tanto en el desarrollo de la explotación de los bosques. Si se mantienen estas políticas relacionadas y consecuentes, entonces, con el enorme volumen de recurso forestal que vendrá en el futuro, aún a raíz solamente de inversiones ya efectuadas, el sector forestal de verdad promete ser un efectivo generador de riqueza para Chile.

(6) Disponibilidad de Madera de Pino Radiata en Chile. 1986-2015. Subcomisión de Inversiones Forestales. INFOR, Santiago, Mayo 1987. Página resumen. Para un mayor detalle respecto a la metodología utilizada, los supuestos involucrados, y los resultados numéricos alcanzados, el lector interesado puede referirse a este documento. Para un resumen más reader friendly de este mismo estudio, véase Cabrera J. Disponibilidad de Madera de Pino Radiata Ciencia e Investigación Forestal, Vol. I N ${ }^{\circ} 1$, INFOR, Santiago, Junio 1987. 
D. WISECARVER y S. TARDONES M.

\section{CUADRO 1}

PLANTACIONES DE PINO RADIATA

$1931-1987$

\begin{tabular}{|c|c|c|c|}
\hline AÑo & TOTAL PAIS & SECTOR PRIVADO & PRIVADO SIN SUBSIDIO \\
\hline $\begin{array}{l}1931-1934 \\
1935-1939 \\
1940-1944 \\
1945-1949 \\
1950-1954 \\
1955 \\
1956 \\
1957 \\
1958 \\
1959 \\
1960 \\
1961 \\
1962 \\
1963 \\
1964 \\
1965 \\
1966 \\
1967 \\
1968 \\
1969 \\
1970 \\
1971 \\
1972 \\
1973 \\
1974 \\
1975 \\
1976 \\
1977 \\
1978 \\
1979 \\
1980 \\
1981 \\
1982 \\
1983 \\
1984 \\
1985 \\
1986 \\
1987\end{array}$ & $\begin{array}{r}921 \\
4.395 \\
27.003 \\
69.858 \\
86.233 \\
6.580 \\
8.600 \\
9.666 \\
9.592 \\
6.595 \\
9.240 \\
8.670 \\
8.002 \\
8.883 \\
8.402 \\
10.554 \\
12.864 \\
14.487 \\
16.566 \\
20.592 \\
30.473 \\
30.996 \\
35.111 \\
33.045 \\
39.113 \\
58.074 \\
91.206 \\
61.903 \\
62.274 \\
52.020 \\
58.402 \\
81.414 \\
56.099 \\
57.855 \\
76.692 \\
80.246 \\
55.058 \\
55.386\end{array}$ & $\begin{array}{c}- \\
- \\
- \\
- \\
- \\
- \\
- \\
- \\
- \\
- \\
- \\
- \\
- \\
- \\
- \\
- \\
- \\
- \\
- \\
- \\
16.497^{*} \\
11.399^{*} \\
6.856 * \\
2.897^{*} \\
21.052 \\
38.463 \\
55.635 \\
48.499 \\
52.486 \\
51.543 \\
58.317 \\
81.385 \\
56.058 \\
36.044 \\
36.390 \\
56.053 \\
55.058 \\
55.386\end{array}$ & $\begin{array}{c}- \\
- \\
- \\
- \\
- \\
- \\
- \\
- \\
- \\
- \\
- \\
- \\
- \\
- \\
- \\
- \\
- \\
- \\
- \\
- \\
- \\
21.052 \\
34.028 \\
8.461 \\
14.825 \\
14.171 \\
5.888 \\
31.577 \\
32.702 \\
4.534 \\
16.490 \\
4.664 \\
22.251 \\
\text { n.d. } \\
\text { n.d. }\end{array}$ \\
\hline
\end{tabular}

Fuente: Para el período 1931-1954, "Inventario de las Plantaciones Forestales de la Zona Centro Sur de Chile". Instituto Forestal. Informe Técnico $\mathrm{N}^{\circ}$ 24. Santiago, Mayo 1966, página 21. Para el período 1955-1964, Banco Mundial, Op. cit., pág. 69. Para la columna "total", 1965-1985, "Disponibilidad de Madera de Pino Radiata en Chile, 1986-2015", Subcomisión de Inversiones Forestales. INFORCORFO, Santiago, Mayo 1987, pág. 44.

Las cifras marcadas con asterisco son de Aninat, Claro y Méndez, Op. cit. pág. 21. Para las demás cifras, "Estadísticas Forestales 1986", INFOR, Santiago, Junio 1987. pág. 30, 32 y 40. 
CUADRO 2

PRODUCCION FISICA DE PRODUCTOS FORESTALES $1930-1987$

\begin{tabular}{|c|c|c|c|c|c|c|}
\hline \multirow[b]{2}{*}{ Año } & \multicolumn{2}{|c|}{ Madera Aserrada } & \multirow{2}{*}{$\begin{array}{l}\text { Pulpa } \\
\text { (mecan. y qui. } \\
\text { miles de ton. }\end{array}$} & \multirow{2}{*}{$\begin{array}{c}\text { Papel p/Period } \\
\text { miles de } \\
\text { toneladas }\end{array}$} & \multirow{2}{*}{$\begin{array}{l}\text { Otros Papeles } \\
\text { y Cartones } \\
\text { miles de ton. }\end{array}$} & \multirow{2}{*}{$\begin{array}{c}\text { Tab. Contrach. } \\
\text { y Chapas } \\
\text { miles de ton. }\end{array}$} \\
\hline & $\begin{array}{l}\text { (miles } \\
\text { de } \mathrm{m}^{3} \text { ) }\end{array}$ & $\begin{array}{c}\text { (\% de Pino } \\
\text { Radiata) }\end{array}$ & & & & \\
\hline 1930 & 111,4 & 0.5 & - & - & - & - \\
\hline 1935 & 550,9 & 0,3 & - & - & - & - \\
\hline 1940 & 646,6 & 6,3 & - & - & - & - \\
\hline 1945 & 862,1 & 4,4 & - & - & - & - \\
\hline 1950 & 618,6 & 9,5 & 19,9 & 11,0 & 33,8 & 6,5 \\
\hline 1951 & 536,2 & 5,1 & 20,3 & 11,0 & 34,8 & 7,8 \\
\hline 1962 & 509,5 & 10,7 & 21,0 & 11,7 & 36,0 & 7,2 \\
\hline 1953 & 692,2 & 6,5 & 19,1 & 9,4 & 41,7 & 7,8 \\
\hline 1954 & 585,0 & 15,9 & - & - & - & 7,8 \\
\hline 1955 & 606,8 & 13,9 & 20,0 & 11,5 & 55,9 & 7,2 \\
\hline 1956 & 684,4 & 9,4 & 20,0 & 11,2 & 55.0 & 2,6 \\
\hline 1957 & 496,1 & 10,9 & 23,7 & 20,2 & 50,6 & 5,4 \\
\hline 1958 & 564,0 & 27,1 & 47,1 & 43,9 & 48,7 & 4,5 \\
\hline 1959 & 646,2 & 31,7 & 60,2 & 48,6 & 56,7 & 10,7 \\
\hline 1960 & 680,6 & 29,6 & 104,9 & 51,6 & 54.3 & 15,4 \\
\hline 1961 & 765,1 & 18,9 & 145,5 & 62,4 & 61,0 & 17.3 \\
\hline 1962 & 775,8 & 22,5 & 146,0 & 54,0 & 71,3 & 18.7 \\
\hline 1963 & 810,2 & 29,4 & 171.7 & 59,8 & 77,1 & 20.5 \\
\hline 1964 & $1.033,0$ & 44,5 & 175,0 & 80,8 & 64.9 & 21,5 \\
\hline 1965 & 994,1 & 48,2 & 199,0 & 96,6 & 74,0 & 27,6 \\
\hline 1966 & $1.061,8$ & 54,4 & 216,6 & 112,1 & 112,0 & 34,1 \\
\hline 1967 & 850.5 & 55,1 & 308,5 & 108,8 & 125,9 & 28,2 \\
\hline 1969 & 996.1 & 57,6 & 278,5 & 115,7 & 114,3 & 42,7 \\
\hline 1969 & $1.012,3$ & 52,8 & 389.7 & 118,4 & 159,3 & 41,9 \\
\hline 1970 & 976,4 & 65,2 & 325,5 & 124,4 & 122,4 & 41,9 \\
\hline 1971 & 1.046 .8 & 70,1 & 345,4 & 111,2 & 166,6 & 47,9 \\
\hline 1972 & 1.113 .6 & 66,0 & 345,0 & 94,7 & 177,3 & 46.5 \\
\hline 1973 & 932,4 & 67,5 & 260,3 & 105,1 & 145.9 & 49,3 \\
\hline 1974 & 1.398 .5 & 77.5 & 432,8 & 118,2 & 188,7 & 50,6 \\
\hline 1975 & 960,0 & 77,5 & 435,8 & 119,7 & 145,8 & 32,9 \\
\hline 1976 & $1.223,3$ & 94,4 & 514,5 & 133,0 & 165,1 & 46.3 \\
\hline 1977 & $1.335,0$ & 96,7 & 603,3 & 132.2 & 167.4 & 55.8 \\
\hline 1978 & 1.475 .0 & 91,7 & 665,0 & 131.9 & 168,6 & 71,2 \\
\hline 1979 & 2.195 .6 & 85,2 & 700,8 & 134,4 & 171,2 & 86,4 \\
\hline 1980 & $2.249,4$ & 84,4 & 763,1 & 131.0 & 195,3 & 88,1 \\
\hline 1981 & $1.731,9$ & 84,0 & 742,6 & 130,7 & 148.2 & 105,3 \\
\hline 1982 & $1.172,4$ & 86,4 & 667,8 & 124,4 & 145.3 & 92.3 \\
\hline 1983 & 1.606 .2 & 88,0 & 796,1 & 155,2 & 169.6 & 104,8 \\
\hline 1984 & $2.001,5$ & 85,4 & 839,4 & 170,4 & 204,6 & 134.5 \\
\hline 1985 & 2.190 .6 & 85,4 & 837,3 & 172,1 & 197,3 & 163.2 \\
\hline 1986 & $2.025,9$ & 86,2 & 847,5 & 168,8 & 219.4 & 164.6 \\
\hline 1987 & 2.677 .1 & 86,3 & 861,0 & 179.5 & 262,4 & 182,6 \\
\hline
\end{tabular}

Fuente: Estadisticas Forestales 1987, INFOR, Santiago, Agosto 1988. 
CUADRO 3

EXPORTACIONES DE PRODUCTOS FORESTALES 1930-1987

\begin{tabular}{|c|c|c|c|c|c|c|c|}
\hline \multirow{2}{*}{ Año } & \multirow{2}{*}{$\begin{array}{c}\text { Madera } \\
\text { Aserrada } \\
\text { (miles } \\
\text { de } \\
\mathrm{m}^{3} \text { ) }\end{array}$} & \multirow{2}{*}{$\begin{array}{c}\text { Pulpa de } \\
\text { Madera } \\
\text { (miles } \\
\text { de } \\
\text { toneladas) }\end{array}$} & \multirow{2}{*}{$\begin{array}{l}\text { Papel para } \\
\text { periodico } \\
\text { (miles } \\
\text { de } \\
\text { toneladas) }\end{array}$} & \multirow{2}{*}{$\begin{array}{l}\text { Tableros, } \\
\text { Contrach. } \\
\text { y Chapas } \\
\text { (miles de } \\
\text { toneladas) }\end{array}$} & \multirow{2}{*}{$\begin{array}{l}\text { Cartulina } \\
\text { p/tarjetas } \\
\text { perforadas } \\
\text { (miles de } \\
\text { toneladas) }\end{array}$} & \multicolumn{2}{|c|}{ Exportaciones Totales } \\
\hline & & & & & & $\begin{array}{l}\text { Millones de } \\
\text { USS FOB }\end{array}$ & $\begin{array}{l}\text { \% de exp. } \\
\text { nacional }\end{array}$ \\
\hline 1930 & 28,8 & - & - & - & - & - & - \\
\hline 1935 & 30,7 & - & - & - & - & - & - \\
\hline 1940 & 18,5 & - & - & - & - & - & - \\
\hline 1945 & 54,7 & - & - & - & - & - & - \\
\hline 1950 & 176.3 & - & - & - & - & - & - \\
\hline 1955 & 198,7 & - & - & - & - & - & - \\
\hline 1960 & 31,9 & 13,7 & 28,9 & - & - & - & - \\
\hline 1961 & 68,2 & 34,0 & 33.7 & - & - & 12,0 & 2,6 \\
\hline 1962 & 47,3 & 23,9 & 24,9 & - & - & 9,7 & 1,9 \\
\hline 1963 & 46,6 & 15,5 & 30,5 & 0,4 & - & 8,0 & 1,6 \\
\hline 1964 & 108,0 & 11,5 & 39,1 & 1,0 & - & 9,7 & 1,6 \\
\hline 1965 & 100,2 & 18,2 & 61,3 & 1,2 & - & 13.7 & 2,0 \\
\hline 1966 & 64,6 & 59,4 & 64,7 & 1,0 & 0,3 & 21,6 & 2,5 \\
\hline 1967 & 48,2 & 77,7 & 66,9 & 0,1 & 14,2 & 26.9 & 3,1 \\
\hline 1968 & 71.2 & 118,2 & 61.1 & 0,3 & 14,8 & 28,2 & 3,1 \\
\hline 1969 & 156,7 & 121,2 & 71,9 & 2,0 & 14,0 & 36,3 & 3.1 \\
\hline 1970 & 150,3 & 105,3 & 78,3 & 0,5 & 18,2 & 41,7 & 3,8 \\
\hline 1971 & 171,1 & 109,3 & 63,9 & 1,3 & 15,9 & 42,5 & 4,4 \\
\hline 1972 & 63,4 & 121,3 & 34,0 & 0,0 & 12,5 & 31,6 & 3,8 \\
\hline 1973 & 67,4 & 97,3 & 32,7 & 0,0 & 10,8 & 36,4 & 2,9 \\
\hline 1974 & 132,6 & 180,6 & 77,5 & 0,1 & 14,2 & 127,0 & 5,9 \\
\hline 1975 & 256,5 & 177,4 & 78,3 & 2,0 & 11,6 & 125,5 & 8,1 \\
\hline 1976 & 412,5 & 283,5 & 92,9 & 11,5 & 14,7 & 169,2 & 8.1 \\
\hline 1977 & 684,4 & 338,8 & 87,4 & 12,7 & 12,2 & 180,6 & 8,2 \\
\hline 1978 & 795,1 & 437,7 & 76,7 & 18,1 & 13,3 & 236,9 & 9,8 \\
\hline 1979 & $1.081,2$ & 431,2 & 75,5 & 24,6 & 22,6 & 349,5 & 9,0 \\
\hline 1980 & $1.295,4$ & 414,8 & 65,4 & 28,7 & 15,0 & 468,1 & 10.1 \\
\hline 1981 & 864,7 & 410,4 & 42,7 & 22.0 & 13,6 & 353,3 & 9,0 \\
\hline 1982 & 618,7 & 462,1 & 54,9 & 34,6 & 9,0 & 332,1 & 9.0 \\
\hline 1983 & 754,9 & 523,4 & 92,2 & 34,1 & 8,5 & 326,2 & 8,5 \\
\hline 1984 & 885,8 & 492,7 & 110,4 & 41,4 & 14,0 & 382.7 & 10.5 \\
\hline 1985 & 706,0 & 503,1 & 116,4 & 43,1 & 10,3 & 334,6 & 8,8 \\
\hline 1986 & 866,4 & 565,2 & 131,5 & 43,4 & 5,2 & 403,1 & 9.6 \\
\hline 1987 & $1.109,9$ & 524,6 & 126,4 & 45,9 & 6,3 & 577.7 & 11,1 \\
\hline
\end{tabular}

Fuente: Estadisticas Forestales 1986, INFOR Santiago, Junio 1987. Para 1987.

Exportaciones Forestales Chilenas (Enero-Diciembre 1987). INFOR, Santiago, Enero 1988, pág. 15. 
SECTOR FOR. CHILENO: POLITICAS, DESARR. RECURSO Y EXPORTACIONES

CUADRO 4

COSTO POR HECTAREA DE PINO RADIATA

(en US\$)

\begin{tabular}{|r|c|c|c|r|r|}
\hline Año & Plantación & Mantención & Poda / Raleo & $\begin{array}{c}\text { Gastos fijos } \\
\text { y Generales }\end{array}$ & Total \\
\hline 1 & 210 & 10,50 & - & 88,20 & 308,70 \\
2 & - & 10,50 & - & 4,20 & 14,70 \\
3 & - & 10,50 & - & 4,20 & 14,70 \\
4 & - & 6,30 & - & 2,52 & 8,82 \\
5 & - & 6,30 & 42,00 & 19,32 & 67,62 \\
6 & - & 6,30 & - & 2,52 & 8,82 \\
7 & - & 6,30 & 21,00 & 10,92 & 38,22 \\
8 & - & 6,30 & - & 2,52 & 8,82 \\
9 & - & 6,30 & 21,00 & 10,92 & 38,22 \\
10 & - & 6,30 & - & 2,52 & 8,82 \\
11 & - & 6,30 & 21,00 & 10,92 & 38,22 \\
12 & - & 6,30 & 168,00 & 69,72 & 244,02 \\
13 & - & 6,30 & - & 2,52 & 8,82 \\
14 & - & 6,30 & - & 2,52 & 8,82 \\
\hline
\end{tabular}

Fuente: Chile: Forest Industries Subsector Study, Banco Mundial, Op. cit. pág. 74.

\section{CUADRO 5}

BOSQUE DE PINO RADIATA DISTRIBUIDO POR EDAD

(hectáreas)

\begin{tabular}{|c|c|c|c|}
\hline \multirow{2}{*}{$\begin{array}{c}\text { RANGO } \\
\text { DE EDAD } \\
\text { EN AÑOS }\end{array}$} & $\mathbf{3}$ & AL MES DE DICIEMBRE DE \\
\cline { 2 - 4 } & $\mathbf{1 9 6 5}$ & $\mathbf{1 9 8 0}$ & $\mathbf{1 9 8 6}$ \\
\hline $1-5$ & 19.663 & 303.994 & 325.122 \\
$6-10$ & 52.612 & 192.220 & 315.261 \\
$11-15$ & 86.233 & 76.959 & 255.438 \\
$16-20$ & 69.858 & 51.974 & 113.799 \\
$21-25$ & 27.003 & 44.655 & 36.986 \\
$26-30$ & 4.395 & 33.898 & 19.483 \\
31 y más & 921 & 13.239 & 70.402 \\
Memo: total & 32.319 & 91.792 & \\
21 años y más & & & \\
\hline
\end{tabular}

Fuente: Para 1965, Inventario de las Plantaciones Forestales de la Zona Centro Sur de Chile, INFOR, Santiago, Mayo 1966, pág. 21. Para 1980, Estad ísticas Forestales 1980, CONAF-INFOR, Santiago, Agosto 1981, pág. 24. Para 1986, Estad ísticas Forestales 1986, INFOR, Santiago, Junio 1987, pág. 27. 
D. WISECARVER y S. TARDONES M.

\section{CUADRO 6 \\ UTILIZACION DE LA MADERA EN TROZO DE PINO RADIATA (miles de $\mathrm{m}^{3}$ )}

\begin{tabular}{|c|c|c|c|c|c|c|}
\hline Año & $\begin{array}{c}\text { Pulpa } \\
\text { Mecánica }\end{array}$ & $\begin{array}{c}\text { Pulpa } \\
\text { Química }\end{array}$ & $\begin{array}{c}\text { Madera } \\
\text { Aserrada }\end{array}$ & $\begin{array}{c}\text { Tableros y } \\
\text { Chapas }\end{array}$ & $\begin{array}{c}\text { Total usos } \\
\text { tradicionales }\end{array}$ & $\begin{array}{c}\text { Exportaciones } \\
\text { de trozos }\end{array}$ \\
\hline 1974 & 297,6 & $1.600,4$ & $2.300,0$ & 108,1 & $4.306,1$ & 0,0 \\
1975 & 275,0 & $1.661,6$ & $1.555,0$ & 62,1 & $3.553,7$ & 6,2 \\
1976 & 311,4 & $1.989,0$ & $2.413,0$ & 83,3 & $4.796,7$ & 17,0 \\
1977 & 313,3 & $2.417,4$ & $1.870,8$ & 128,6 & $4.730,1$ & 146,7 \\
1978 & 323,4 & $2.731,3$ & $2.826,9$ & 129,4 & $6.011,0$ & 674,4 \\
1979 & 325,8 & $2.871,7$ & $3.909,7$ & 163,0 & $7.270,2$ & 954,1 \\
\hline
\end{tabular}

Fuente: Estadísticas Forestales 1986, INFOR, Santiago, Junio de 1987, pág. 47.

\section{CUADRO 7 \\ NUEVOS PRODUCTOS DE EXPORTACION}

$(1974$ - 1987)

\begin{tabular}{|c|c|c|c|c|}
\hline \multirow{2}{*}{ AÑo } & \multirow{2}{*}{$\begin{array}{c}\text { MADERA } \\
\text { EN TROZOS } \\
\left(\text { miles de } \mathrm{m}^{3}\right)\end{array}$} & \multicolumn{2}{|c|}{ MADERA PULPABLE } & \multirow{2}{*}{$\begin{array}{c}\text { MADERA } \\
\text { ELABORADA } \\
\left(\text { miles de } \mathrm{m}^{3}\right)\end{array}$} \\
\hline & & $\begin{array}{c}\text { Trozos } \\
\left(\text { miles de } \mathrm{m}^{3} \text { ) }\right.\end{array}$ & $\begin{array}{c}\text { Astillas } \\
\text { (miles de toneladas) }\end{array}$ & \\
\hline 1974 & 0,0 & 0,0 & 0,0 & 0,0 \\
\hline 1975 & 6,2 & 0,0 & 0,0 & 0,0 \\
\hline 1976 & 17,0 & 0,0 & 0,0 & 0,0 \\
\hline 1977 & 147,6 & 0,0 & 0,0 & 0,0 \\
\hline 1978 & 679,2 & 0,0 & 0,0 & 0,0 \\
\hline 1979 & 965,7 & 0,0 & 0,0 & 0,0 \\
\hline 1980 & $1.052,4$ & 0,0 & 0,0 & 0,0 \\
\hline 1981 & 361,0 & 0,0 & 0,0 & 0,0 \\
\hline 1982 & 892,0 & 0,0 & 0,0 & 0,0 \\
\hline 1983 & $1.026,3$ & 0,0 & 0,0 & 3,9 \\
\hline 1984 & 905,6 & 0,0 & 0,0 & 15,8 \\
\hline 1985 & $1.259,5$ & 13,9 & 0,0 & 72,1 \\
\hline 1986 & $1.024,9$ & 138,8 & 124,2 & 117,7 \\
\hline 1987 & $1.219,8$ & 676,7 & 452,5 & 142,4 \\
\hline
\end{tabular}

Fuente: Estadísticas Forestales 1986, INFOR, Santiago, Junio 1987. Para 1987, Exportaciones Forestales Chilenas (Enero-Diciembre 1987), INFOR, Santiago, Enero 1988, pág. 15. 
SECTOR FOR. CHILENO: POLITICAS, DESARR. RECURSO Y EXPORTACIONES

\section{CUADRO 8 \\ RENDIMIENTOS Y COSTOS DE EMBARQUE EN LOS PUERTOS DE LA VIII REGION}

\begin{tabular}{|c|c|c|}
\hline & 1982 & 1984 \\
\hline $\begin{array}{l}\text { RENDIMIENTOS } \\
\text { Celulosa (toneladas / día) } \\
\text { Troncos }\left(\mathrm{m}^{3} / \text { día }\right) \\
\text { Madera }\left(\mathrm{m}^{3} / \text { día) }\right.\end{array}$ & $\begin{array}{c}1.800 / 2.000 \\
2.800 \\
2.500\end{array}$ & $\begin{array}{c}5.000 / 6.000 \\
5.500 \\
5.000\end{array}$ \\
\hline $\begin{array}{l}\text { COSTO ESTIBA } \\
\text { Celulosa (US } \$ / \text { toneladas) } \\
\text { Papel (US\$/toneladas) } \\
\text { Troncos (US } \$ / \mathrm{m}^{3} \text { ) } \\
\text { Madera (US } \$ \mathrm{~m}^{3} \text { ) }\end{array}$ & $\begin{array}{c}8,00 \\
9,00 \\
4,50 / 5,00 \\
6,00\end{array}$ & $\begin{array}{l}2,00 \\
2,50 \\
1,00 \\
1,30\end{array}$ \\
\hline
\end{tabular}

Fuente: J.M. Mendia Situación portuaria, documento de trabajo, Abril 1984.

\section{REFERENCIAS BIBLIOGRAFICAS}

1. AEDO, C. Y LAGOS, L.F. Protección Efectiva en Chile, 1974-1979". Documento de Trabajo $\mathrm{N}^{\circ}$ 94. Instituto de Economía, Universidad Católica de Chile. Santiago. 1984.

2. ANINAT, CLARO Y MENDEZ, Economistas Consultores Asociados Ltda. "Estudio Económico de los Costos y Beneficios Asociados al D.L. 701 de Fomento Forestal", Santiago, 1982.

3. BANCO MUNDIAL, "Chile Forest Industries Sub-sector Study", Washington, 1986.

4. CABRERA, J. "Disponibilidad de Madera de Pino Radiata". Ciencia e Investigación Forestal, Vol. I, N ${ }^{\circ}$ INFOR, Santiago, Junio 1987.

5. CAUAS, J. Y DE LA CUADRA, S. "La Política Económica de la Apertura al Exterior en Chile", Cuadernos de Economía, Agosto-Diciembre 1981.

6. DE LA CUADRA, S. Y HACHETTE, D. "The Timing and Sequencing a Trade Liberalization Policy. The Case of Chile" (documento preparado para el Banco Mundial) Instituto de Economía, Universidad Católica de Chile. Santiago, Diciembre 1986.

7. GANA, J. "Análisis y Perspectivas del Sector Forestal", Tesis Ing. Ind. Universidad de Chile, Facultad de Ciencias Físicas y Matemáticas, Santiago, 1982.

8. INSTITUTO FORESTAL (INFOR) "Inventario de las Plantaciones Forestales de la Zona Centro Sur de Chile", Informe Técnico $\mathrm{N}^{\circ} 24$, Santiago, Mayo 1966.

9. Boletín Estad ístico Anual, 1974, Santiago, 1974.

10. INFOR-CORFO, Estad ísticas Forestales 1985, Santiago, Junio 1986.

11. Estadísticas Forestales 1986, Santiago, Junio 1987.

12. "El Mercado Internacional y las Exportaciones Forestales Chilenas", Informe Técnico $\mathrm{N}^{\circ} 110$, Santiago, Octubre 1987.

13. "Exportaciones Forestales Chilenas (Enero-Diciembre 1987)" Santiago, Enero 1988.

14. LUDERS, R. "Inversiones Agrosilvícolas para la Exportación" Departamento de Economía Agraria, Universidad Católica de Chile, Santiago, Marzo 1985.

15. MENDIA, J. "Situación Portuaria", Documento de Trabajo, Abril 1984.

16. SJAASTAD, L. "Protección y el Volumen de Comercio: La Evidencia": Cuadernos de Economía, Agosto-Diciembre 1981.

17. SUBCOMISION DE INVERSIONES FORESTALES, "Disponibilidad de Madera de Pino Radiata en Chile: 1986-2015", INFOR-CORFO, Santiago, Mayo 1987.

18. WISECARVER, D. Regulación y derregulación en Chile, Septiembre 1973-Septiembre 1983", Estudios Públicos, Otoño 1986. 